\title{
Experimental Study of Filling Ratio Effect on the Thermal Performance in a Multi-Heat Pipe with Graphene Oxide/Water Nanofluids
}

\author{
Mohamed Salem ${ }^{1,2^{*}}$, Tarek A. Meakhail'1, Magdy A. Bassily ${ }^{3}$, Shuichi Torii ${ }^{2}$ \\ ${ }^{1}$ Department of Mechanical Engineering, Faculty of Energy Engineering, Aswan University, Aswan, Egypt \\ ${ }^{2}$ Graduate School of Science and Technology, Kumamoto University, Kumamoto, Japan \\ ${ }^{3}$ Department of Mechanical Engineering, Faculty of Engineering, Minia University, Minia, Egypt \\ Email: *Mohamed_salem@Aswu.edu.eg
}

How to cite this paper: Salem, M., Meakhail, T.A., Bassily, M.A. and Torii, S. (2016) Experimental Study of Filling Ratio Effect on the Thermal Performance in a MultiHeat Pipe with Graphene Oxide/Water Nanofluids. World Journal of Nano Science and Engineering, 6, 153-164.

http://dx.doi.org/10.4236/wjnse.2016.64014

Received: November 28, 2016

Accepted: December 18, 2016

Published: December 21, 2016

Copyright $\odot 2016$ by authors and Scientific Research Publishing Inc. This work is licensed under the Creative Commons Attribution International License (CC BY 4.0).

http://creativecommons.org/licenses/by/4.0/

\begin{abstract}
This experimental study is performed to investigate heat transfer performance of a multi-heat pipe cooling device in the condition of different filling ratios $(40 \%, 60 \%$, $80 \%$ and $100 \%)$ and different constant heat fluxes (10 - $30 \mathrm{~W}$ ). Here, pure water (distilled water) and graphene oxide (GO)/water nanofluids are employed respectively as working fluid. GO/water nanofluids were synthesized by the modified Hummers method with $0.05 \%, 0.10 \%, 0.15 \%$, and $0.20 \%$ volume concentrations. Multi-heat pipe is fabricated from copper; the heating and cooling sections are the same size and both are connected by four circular parallel tubes. Temperature fields and thermal resistance are measured for different filling ratio, heat fluxes and volume concentrations. The results indicated that the thermal performance of heat pipe increased with increasing the concentration of GO nanoparticles in the base fluid, while the maximum heat transfer enhancement was observed at $0.20 \%$ volume concentration. GO/ water nanofluids showed lower thermal resistance compared to pure water; the optimal thermal resistance was obtained at $100 \%$ filling charge ratio with $0.20 \%$ volume concentration. Studies were also demonstrated that heat transfer coefficient of the heat pipe significantly increases with increasing the input heat flux and GO nanoparticles concentration.
\end{abstract}

\section{Keywords}

Multi-Heat Pipe, Graphene Oxide, Filling Ratio, Volume Fraction, Thermal Resistance

\section{Introduction}

A multi-heat pipe is a device that transfers heat from the hot interface to the cold one 
by phase change and convection of the working fluid. Vapor is generated at the heat source level (evaporator) and it condenses at the heat sink level (condenser). The liquid returns from the evaporator to the condenser through a capillary structure. Heat pipes have a variety of advantages, such as high heat removal rate per unit volume, a fully passive working principle, and easy applicability. Heat pipes have been used in various thermal engineering fields such as computer CPUs, solar energy collectors and micro device transmitting equipment.

Kim K. and Bang I. [1] experimentally observed the effect of the working fluid fill ratio and the cross sectional area of the vapor path on the heat removal capacity and thermal performance of an annular thermosyphon that contains a neutron absorber. They observed that increasing the fill ratio enhanced the entrainment limit by $18 \%$. Sarafraz M. and Hormozi F. [2] studied experimentally the effect of different operating parameters such as applied heat flux to the evaporator section, fill charge ratio of working fluid, tilt angle of the heat pipe and volume concentration of nanoparticle on the thermal performance and efficiency of the thermosyphon heat pipe. At $5 \mathrm{vol} \%$, the best fill charge ratio is $50 \%$ and $70 \%$ for alumina-water/EG and alumina-water/DEG nanofluids respectively. Lips S. et al. [3] carried out experiments to observe the effect of the filling ratio and vapor space thickness on the thermal performance of a flat plate heat pipe (FPHP) using n-pentane in horizontal orientation. They concluded that a small vapor space thickness induces liquid retention in the FPHP sides and corners and thus reduces the thermal resistance of the system even for a liquid quantity greater than the optimum value. Mameli M. et al. [4] focused on the combined effect of the inclination angle and filling ratio at different heat input levels on the device operation stability and the thermal performances of a multi-turn closed loop pulsating heat pipe (CLPHP) made of copper. The test fluid was FC-72. Results showed that this CLPHP is very much sensitive to the inclination angle and that the vertical operation is affected by unstable operation at high input levels. At 0.5 filling ratio, the best performance was obtained and the minimum with $0.7 \mathrm{FR}$. Barua $\mathrm{H}$. et al. [5] investigated experimentally the thermal performance of a closed loop pulsating heat pipe using two different working fluids (water and ethanol) at various filling ratios (100\%, 82.5\%, 63\%, 41.3\% and $28 \%$ ). For water at lower and higher heat input, lower filling ratio showed less thermal resistance and optimum heat transfer was obtained at nearly $30 \%$ filling ratio. For ethanol at low heat input, the best performance was obtained at high filling ratio beyond $50 \%$ in the basis of heat transfer. For high heat input, ethanol showed high heat transfer rate at high heat input for all filling ratio. Pote A. and Pachghere [6] performed an experiment using $\mathrm{ZnO} /$ water nanofluid of $100 \mathrm{~nm}$ to investigate the effect of concentration of zinc oxide nanoparticles on thermal resistance of a closed loop pulsating heat pipe (CLPHP). Experiment was conducted in vertical orientation with 50\% filling ratio. They found that thermal resistance of CLPHP using $\mathrm{ZnO}$ /water nanofluid as working fluid was better than thermal resistance when pure water is used. Verma B. et al. [7] studied experimentally the effect of filling charge ratio, inclination angle and heat flux on the start-up and thermal performance in terms of thermal resistance and heat transfer coefficient of 
a pulsating heat pipe using methanol and de-ionized (DI) water. They concluded that the minimum start-up power and thermal resistance were obtained at 50\% and $40 \%$ filling ratio for DI water and methanol, respectively. Qu J. et al. [8] investigated experimentally the performance of a stainless steel oscillating heat pipe (OHP) charged with base water and spherical $\mathrm{Al}_{2} \mathrm{O}_{3}$ particles of $56 \mathrm{~nm}$ in diameter. The effects of filling ratios, mass fractions of alumina particles and power inputs on the total thermal resistance of the OHP were investigated. They showed that the maximum thermal resistance was decreased by $0.14^{\circ} \mathrm{C} / \mathrm{W}$ (or 32.5\%) when the power input was $85.8 \mathrm{~W}$ at $70 \%$ filling ratio and $0.9 \%$ mass fraction. Lin Y. et al. [9] studied the effect of silver nanofluid (20 $\mathrm{nm}$ in diameter) on copper pulsating heat pipe thermal performance. The thermal performance was studied at different concentration (100 ppm and $450 \mathrm{ppm})$, various filled ratio $(20 \%-80 \% \mathrm{FR})$ and different heat power $(5 \mathrm{~W}-85 \mathrm{~W})$. The results showed that the best filled ratio was $60 \%$ and the better working fluid was $100 \mathrm{ppm}$ of silver nanofluid. Khandekar S. et al. [10] investigated the effect of working fluid (water, ethanol and R-123) and filling ratio on the thermal performance of closed loop pulsating heat pipe in vertical and horizontal orientation. They found that the best performance was measured at low filling ratio for all working fluids. Salem M. et al. [11] measured thermal conductivity of graphene oxide/water nanofluid with different volume concentration ranged from $0.05 \%$ to $0.2 \%$ using transient hot wire method (KD2 thermal property meter). They showed that the thermal conductivity was enhanced with reference to pure water. Also, it was increased by increasing nanoparticles concentration.

In the present work, experimental studies have been conducted on the thermal performance of a copper multi-heat pipe charged with pure water (distilled water) and graphene oxide (GO)/water nanofluids as working fluid. The experiment was performed at different volume concentrations $(0.05,0.10,0.15$ and 0.20 vol\%), various filling charge ratios $(40 \%, 60 \%, 80 \%$ and $100 \% \mathrm{FR})$ and different heat fluxes $(10 \mathrm{~W}-30 \mathrm{~W})$.

\section{Materials and Methods}

\subsection{Materials}

Graphene oxide (GO)/water nanofluids were prepared by dispersing $\mathrm{GO}$ nanoparticles into pure water as a base fluid. GO nanoparticles were synthesized from natural graphite powder by a modified Hummers method [11] [12]. Graphite fine powders (45 $\mu \mathrm{m}$ ) was purchased from Wako pure chemical industries (Japan), concentrated sulfuric acids $\left(\mathrm{H}_{2} \mathrm{SO}_{4}\right)$, sodium nitrate $\left(\mathrm{NaNO}_{3}\right)$, potassium permanganate $\left(\mathrm{KMnO}_{4}\right)$, hydrogen peroxide $\left(30 \% \mathrm{H}_{2} \mathrm{O}_{2}\right)$, hydrochloric acid $(5 \% \mathrm{HCl})$ and deionized water were used throughout Hummers method. GO/water nanofluids with four different volume concentrations at $0.05 \%, 0.10 \%, 0.15 \%$ and $0.20 \%$ were prepared for this experiment. The thermal conductivity and the viscosity of GO/water nanofluids were measured in our previous study [11].

\subsection{Test Section}

Figure 1 represents a multi-heat pipe which consists of evaporator, adiabatic section 

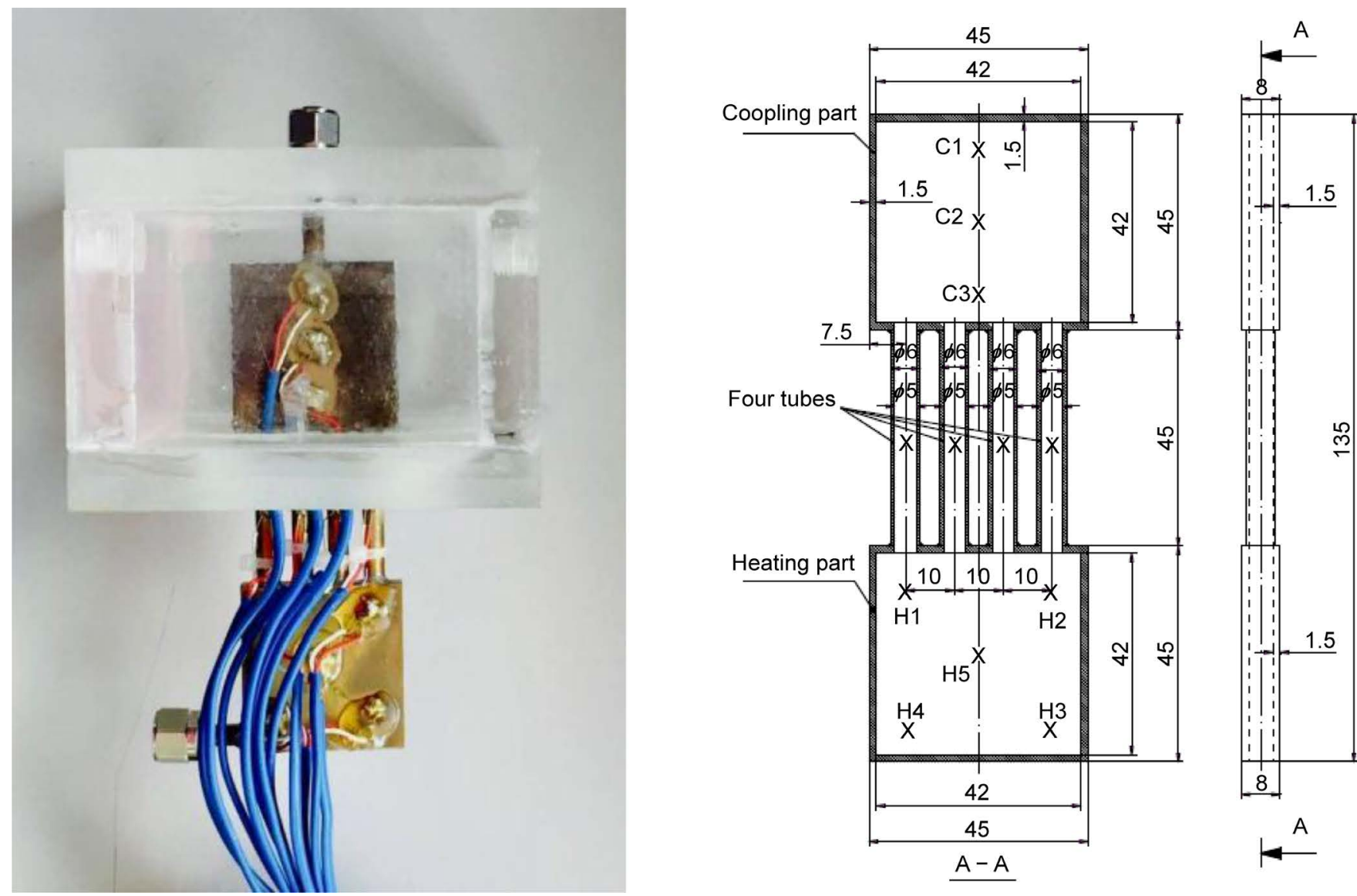

Figure 1. Multi-heat pipe with thermocouple locations (all dimensions are in $\mathrm{mm}$ ).

and condenser. A multi-heat pipe was made of copper in laboratory of Kumamoto university-Japan. The external dimensions for heating and cooling sections are $45 \times 45$ $\times 8 \mathrm{~mm}$, and the internal dimensions are $42 \times 42 \times 5 \mathrm{~mm}$. The adiabatic section is consisted of four parallel circular tubes whose dimension is $\phi 6$ (external diameter) $\times \phi 5$ (inlet diameter) $\times 45 \mathrm{~mm}$ (length). As shown in figure, twelve k-type thermocouples were installed on the test section, with five of them embedded in the evaporator section $\left(\mathrm{H}_{1}, \mathrm{H}_{2}, \mathrm{H}_{3}, \mathrm{H}_{4}\right.$, and $\left.\mathrm{H}_{5}\right)$, four in the adiabatic section $\left(\mathrm{a}_{1}, \mathrm{a}_{2}, \mathrm{a}_{3}\right.$, and $\left.\mathrm{a}_{4}\right)$, and three in the condenser $\left(\mathrm{C}_{1}, \mathrm{C}_{2}\right.$, and $\left.\mathrm{C}_{3}\right)$.

\subsection{Experimental Setup and Procedures}

As shown in Figure 2, the experimental setup consists of a test section (multi-heat pipe) which connected with burette (NALJENE, USA) to calculate the amount of working fluid that filled the heat pipe. Vacuum pump (ULVAC KIKO, Japan) was connected with vacuum gauge to generate vacuum pressure inside the heat pipe. The evaporator section was electrically heated by heater block (HAKKO, Japan) made from copper containing five heaters (five heaters are not shown in the figure) which connected with transformer (YAMABISHI, Japan) and its voltage and power were measured by digital multi-meter (HIOKI, Japan). The condenser section was cooled by 


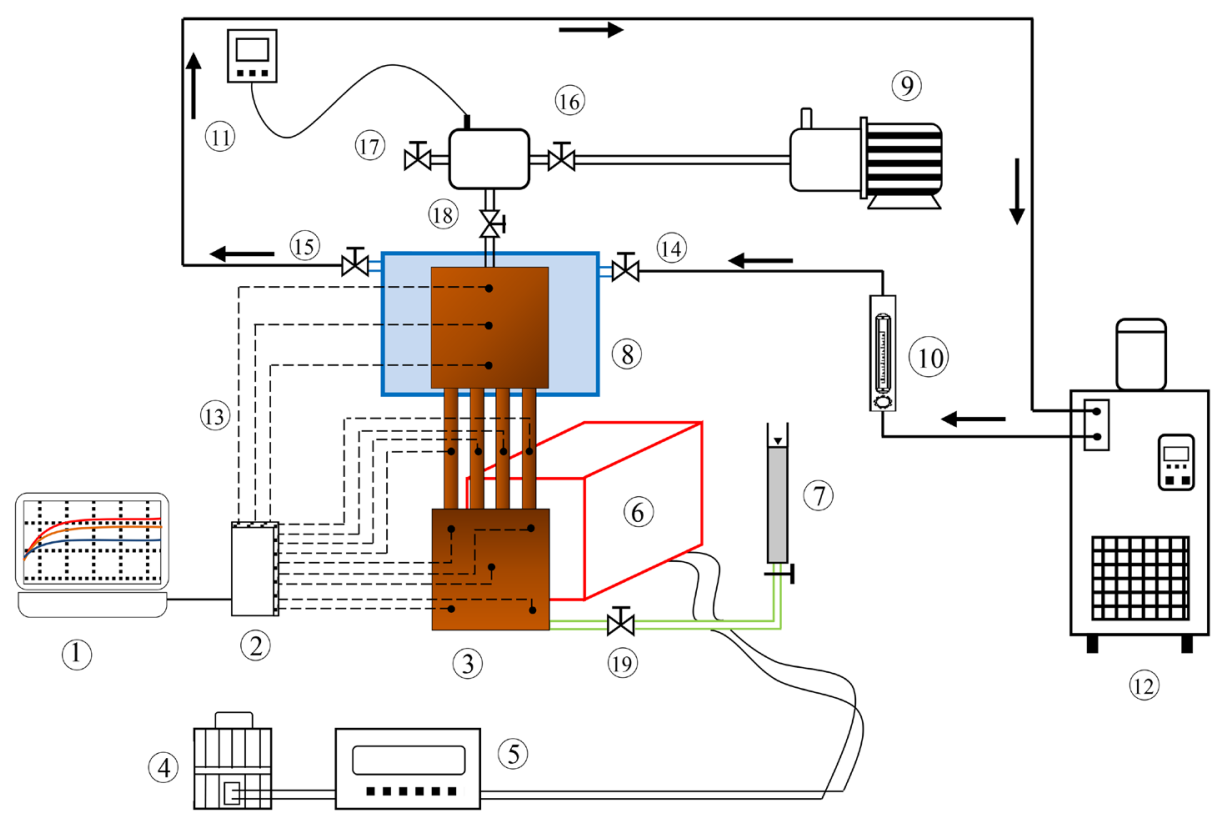

(1) Personal Computer
(2) Data Logger
(3) Multi-Heat Pipe
(4) Transformer

(5) Digital Multi-Meter

(6) Heater Block

(7) Burette

(9) Vacuum Pump

(13) Thermocouples

(8) Water Tank

(10) Flow Meter

(11) Vacuum Gauge

(12) Thermostatic Bath

(14) (15) Flow control Valve

(16) (17) (19) Vacuum Valve

Figure 2. Schematic of experimental set-up.

immersing it into the plastic cooling chamber and water was used as the coolant fluid which pumped from the thermostatic bath (NCC-1100, Japan). The cooling water flow rate was measured by flow meter (KOFLOC, Japan). Both evaporator and adiabatic sections were thermally insulated with glass fiber to prevent heat loss. The surface temperatures of the heat pipe were measured using twelve k-type thermocouples (Figure $1)$.

The test section was evacuated using the vacuum pump to remove the non-condensable gases. Cooling water was then supplied from thermostatic bath to the cooling chamber at a volume flow rate of $1.5 \mathrm{l} / \mathrm{min}$ and $15^{\circ} \mathrm{C}$. The test section was then charged with the working fluid. The filling charge ratios (FR) (volume ratio of the working fluid to the internal volume of the evaporator section) were varied at $40 \%, 60 \%, 80 \%$ and $100 \%$ for each working fluid. The vacuum pressure inside the test section was set to 9.5 $\mathrm{kPa}$ for all cases. The test section was heated gradually until a steady state was attained.

\section{Results and Discussion}

The experiments are carried out by using four various filling ratios $(40 \%, 60 \%, 80 \%$ and $100 \%$ ) with multi-heat pipe kept in vertical position (the evaporator section at the bottom and condenser section at the top). Heat pipe with pure water as working fluid used in the comparison of results to understand the effects of volume concentration of $\mathrm{GO} /$ water nanofluids on the heat pipe thermal performance with different filling charge ratios and input heat power. 


\subsection{Wall Temperature of Heat Pipe}

The evaporator and condenser wall temperature are therefore calculated as the arithmetic average of the thermocouples located in the evaporator and condenser sections. The mean temperature of evaporator and condenser sections are calculated and plotted against the heat load at different volume concentrations and filling ratios in Figure 3.

The results indicate that an increase of heat flux leads to increase the evaporator and condenser wall temperature at different volume concentration and filling ratio. This is due to high heat flux causes an increase of the evaporation of working fluid leading to increase pressure in the heat pipe affecting higher saturation temperature of working
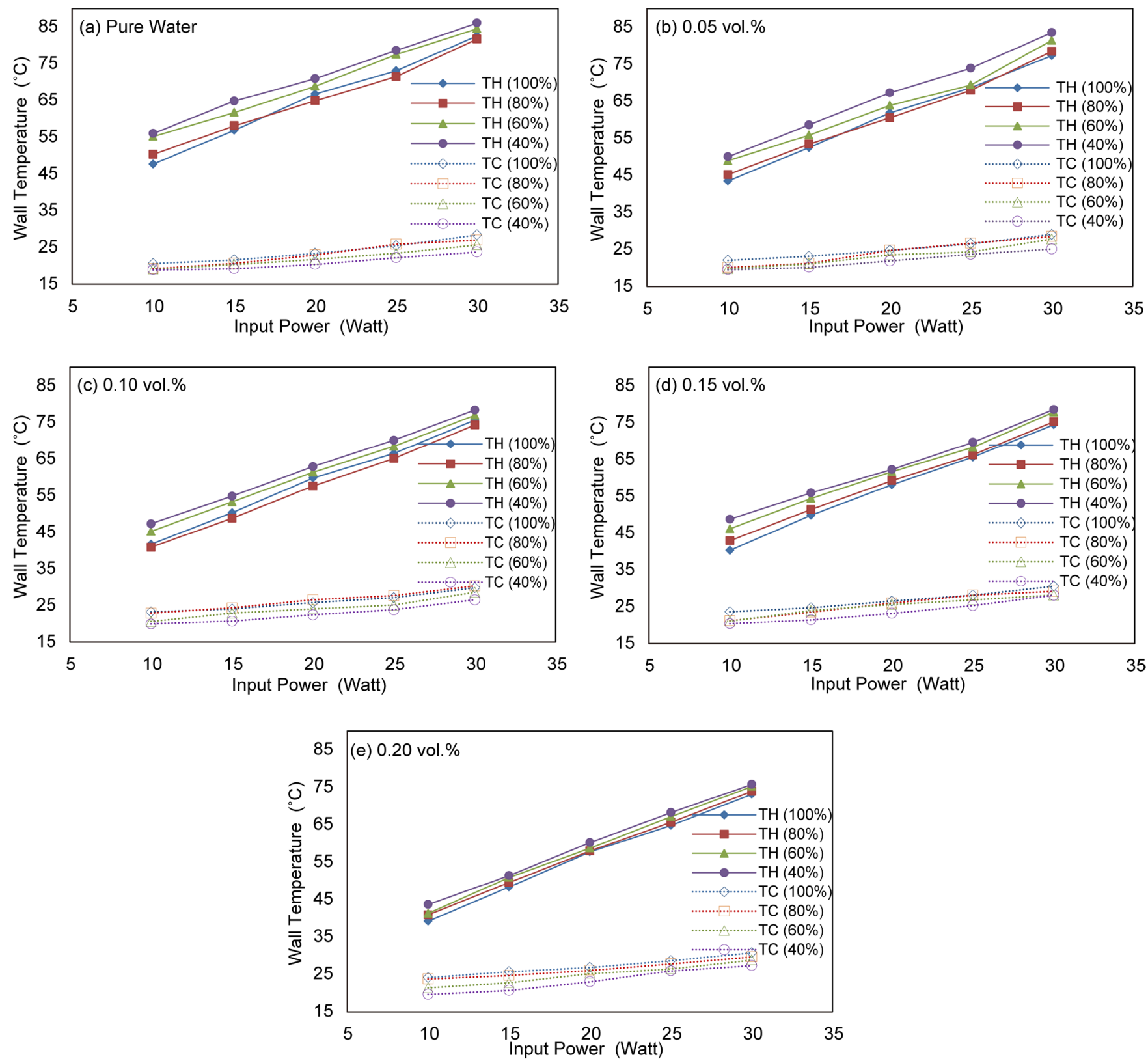

Figure 3. Wall temperatures as a function of input heat load and filling ratio. 
fluid in heat pipe. The wall temperature of the heat pipe reduces from evaporator to condenser section. Also, a rough comparison between pure water and $\mathrm{GO} /$ water nanofluids shows that presence of GO nanoparticles significantly reduces the evaporator temperature and slightly increases the condenser temperature, which means that the thermal performance of the heat pipe greatly enhances, when GO nanoparticles are added into pure water.

Based on the experimental results, the mean wall temperature of evaporator reduced as the filling charge ratio increased for volume concentration $0.15 \%$ and $0.20 \%$ at the same input heat flux. For pure water (distilled water), $0.05 \%$ and $0.10 \%$ volume concentration, evaporator temperature decreases with the rise of filling ratio till $80 \%$, but it decreased when the filling ratio reached $100 \%$ for $0.10 \mathrm{vol} \%$ at different heat load and after $15 \mathrm{~W}$ for pure water and $0.05 \%$ volume concentration. The condenser temperature increases in slow rate with increment of filling ratio. The highest condenser temperature is obtained at $100 \%$ filling ratio for pure water, $0.05,0.15$ and $0.20 \mathrm{vol} \%$ and at $80 \%$ for $0.10 \%$ volume concentration.

For $0.20 \%$ volume concentration, the rate of change of evaporator wall temperature with different filling ratio is very small because the viscosity is too high [11]. The maximum percentage of temperature reduction in the evaporator section compared with pure water is obtained at $0.20 \%$ volume fraction (the temperature reduced by $17.82 \%$, $18.76 \%, 25.24 \%$ and $22.10 \%$ for $100 \%, 80 \%, 60 \%$ and $40 \%$ filling ratio, respectively).

\subsection{Thermal Resistance}

The thermal performance of the multi-heat pipe can be characterized by the overall thermal resistance $\left(R_{t h}\right)$. The overall thermal resistance results from the combination of both the condenser and evaporator thermal resistance, which defined as the ratio of the temperature difference to a given heat load:

$$
R_{t h}=\frac{T_{H}-T_{C}}{Q}
$$

where $T_{H}$ is the mean evaporator wall temperature, $T_{C}$ is the mean wall temperature of the condenser and $Q$ is the input heat load.

Considering that the heat loss from the evaporator and adiabatic sections of the multi-heat pipe to ambience was negligibly small due to good insulation, heating power input $Q$ can be evaluated as follows:

$$
Q=V \times I
$$

where $V$ and $I$ are the applied voltage and current, respectively.

Figure 4 shows the overall thermal resistances of multi-heat pipe as a function of input heat load and filling charge ratio for each volume concentration. It can be seen that the thermal resistance tends to decrease with increasing heat flux. This is because the heat flux increases which results in lower of the temperature difference between evaporator section and condenser section. Therefore, the overall thermal resistance decreases since heat flux has increased. Noticeably, with increasing heat fluxes from $10 \mathrm{~W}$ 

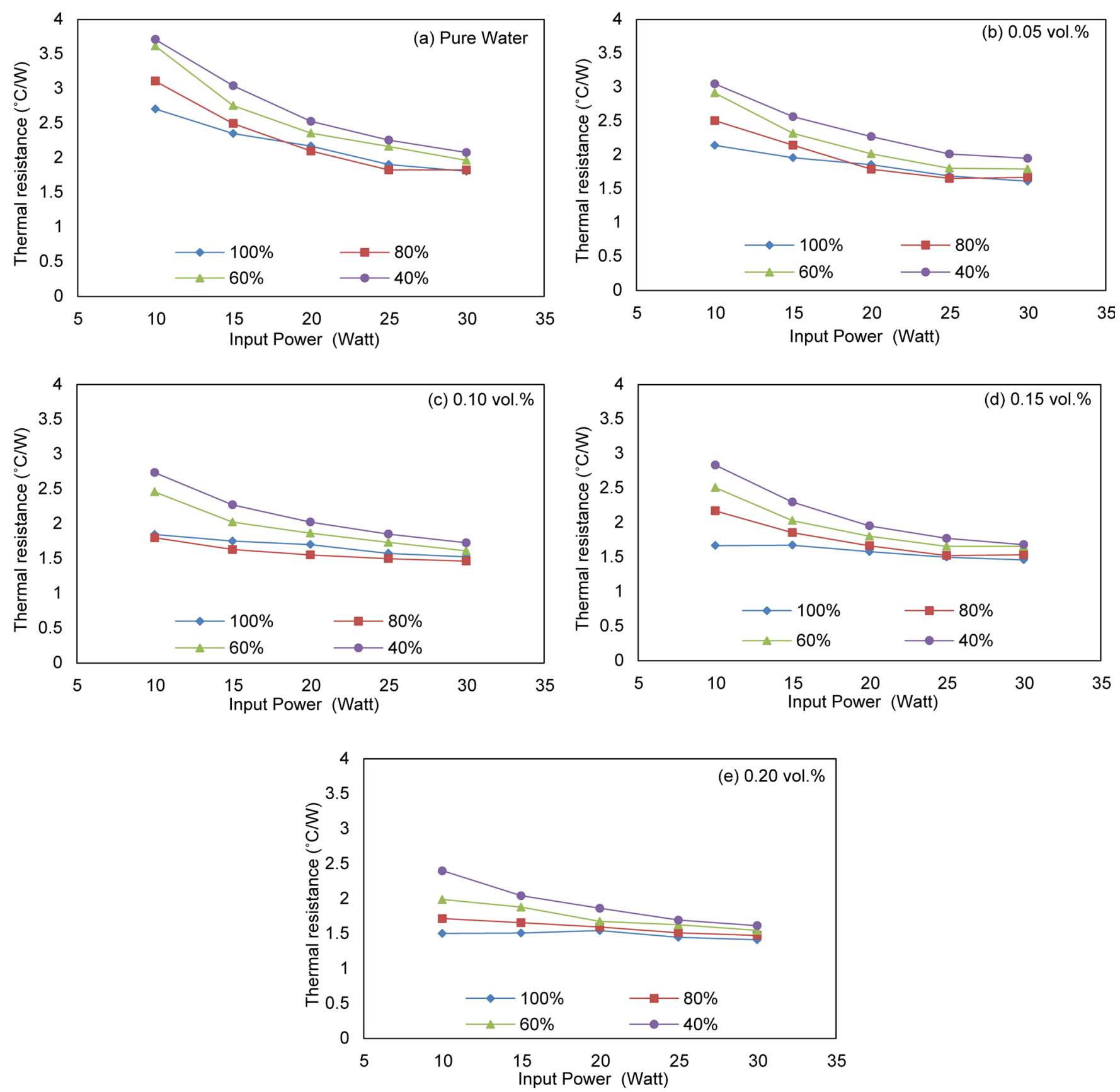

Figure 4. Thermal resistances as a function of input heat load and filling ratio.

to $20 \mathrm{~W}$, thermal resistance of heat pipe dramatically decreased for all working fluids at $40 \%-80 \%$ filling ratio. For all concentrations of GO/water nanofluids, a lower thermal resistance is reported and subsequently, a higher heat transfer performance can be registered in comparison with pure water. The heat pipe with a higher concentration of nanoparticles has a lower thermal resistance than that of charged with lower concentration. The thermal resistance decreased with increasing filling charge ratios of working fluids from $40 \%$ to $80 \%$, but it increased when the filling ratio reached $100 \%$ for $0.10 \%$ 
volume fraction. The lowest overall thermal resistance is obtained at $80 \%$ filling ratio for $0.10 \%$ volume concentration and at $100 \%$ for $0.15 \%$ and $0.20 \%$ volume concentration at different heat load. For pure water and $0.05 \%$ volume concentration, the lowest thermal resistance is obtained at $80 \%$ filling ratio when the heat load is higher than $15 \mathrm{~W}$. As compared with pure water, the maximal decrease of the thermal resistance was about $1.20^{\circ} \mathrm{C} / \mathrm{W}, 1.39^{\circ} \mathrm{C} / \mathrm{W}, 1.63^{\circ} \mathrm{C} / \mathrm{W}$ and $1.31^{\circ} \mathrm{C} / \mathrm{W}$ (or $44.45 \%, 44.82 \%, 44.98 \%$ and $35.27 \%$, respectively) which occurred at $100 \%, 80 \%, 60 \%$ and $40 \%$ filling ratio, respectively, when the power input was $10 \mathrm{~W}$ for maximum volume concentration $0.20 \%$. Thus, the addition of GO nanoparticles in the base fluid (pure water) enhanced the thermal resistance of the multi-heat pipe.

The GO/water nanofluids can enhances the thermal resistance with different reason: the presence of nanoparticles in base fluid increases the thermal conductivity of base fluid. Reason for enhancement of thermal conductivity is micro-conductive between solid and liquid molecules, Brownian motion of nanoparticles and clustering in nanofluid.

\subsection{Overall Heat Transfer Coefficient}

The overall heat transfer coefficient $(h)$ of the heat pipe calculated using the surface temperature of evaporator and condenser section using Equation (3).

$$
h=\frac{Q}{A_{e}\left(T_{H}-T_{C}\right)}
$$

where $A_{e}$ is the cross section area of the evaporator section.

Figure 5 shows the overall heat transfer coefficient against the heat load for all the filling charge ratios and the volume concentrations. For GO/water nanofluid, a higher heat transfer coefficient is registered for all volumetric concentrations of nanoparticles in comparison with those reported for pure water at a similar condition. The GO nanoparticles in the heat pipe not only increased the fluid thermal conductivity but also enhanced the heat transfer coefficient due to the particles migration. It is clear from Figure 5 that the increase of the heat load improved the heat transfer coefficient of the heat pipe for each filling ratio.

Results demonstrated that the heat transfer coefficient of heat pipe drastically increases with increasing the filling charge ratio at the same input heat fluxes, because the temperature difference between the evaporator and condenser section decreases with increasing the filling charge ratio. The optimum heat transfer coefficient was obtained at $100 \%$ filling ratio for 0.15 vol.\% and 0.20 vol. $\%$ and at $80 \%$ for $0.10 \%$ volume concentration. For pure water and 0.05 vol.\%, the heat transfer coefficient increases with the rise of filling ratio till $15 \mathrm{~W}$ input heat load. Beyond $15 \mathrm{~W}$, the maximum heat transfer coefficient was obtained at $80 \%$ filling ratio.

\section{Conclusion}

In this work, thermal characterizations of a copper multi-heat pipe were experimentally performed with five different heat fluxes $(10 \mathrm{~W}, 15 \mathrm{~W}, 20 \mathrm{~W}, 25 \mathrm{~W}$ and $30 \mathrm{~W})$, four 

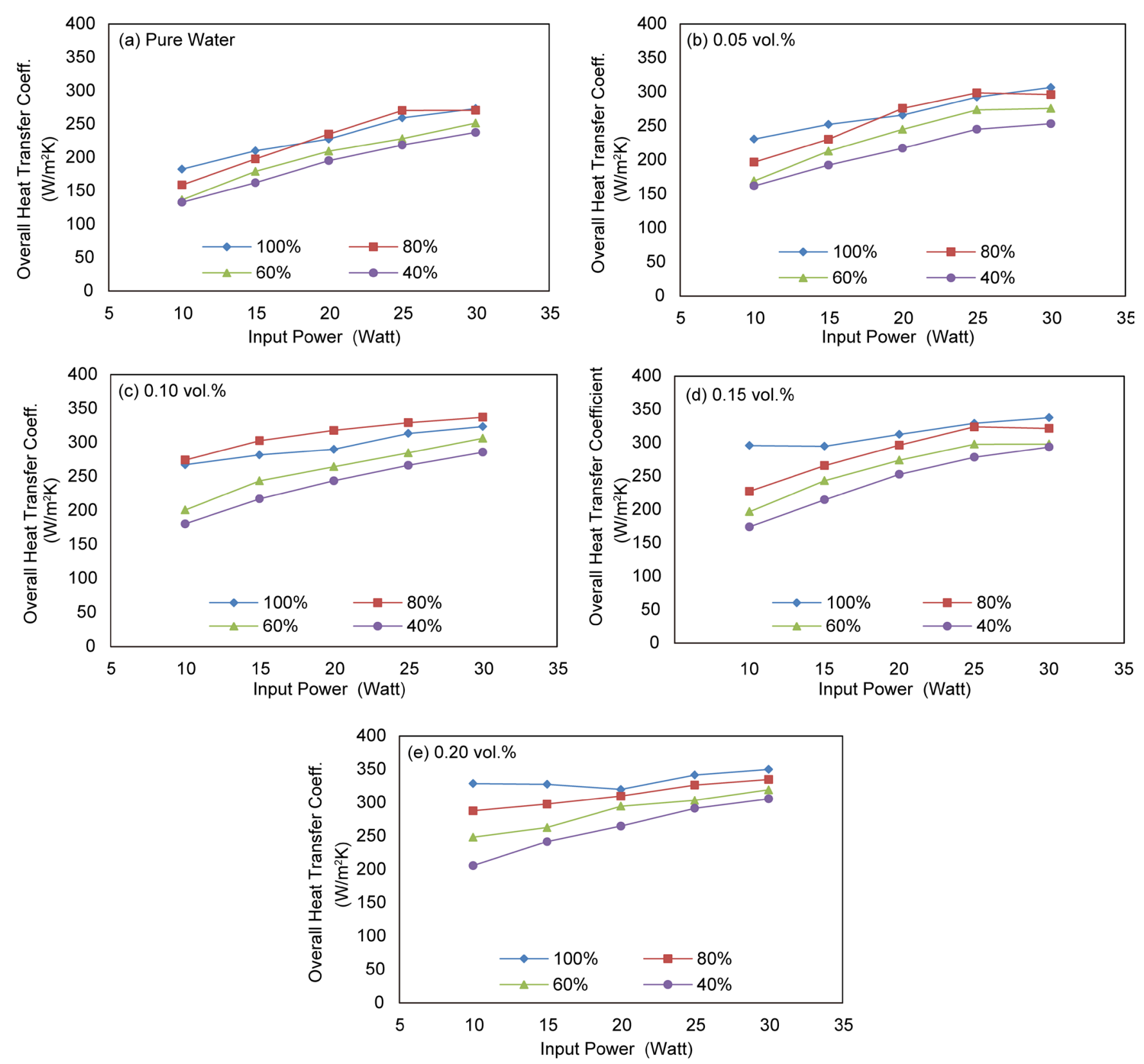

Figure 5. Overall heat transfer coefficient as a function of input heat load and filling ratio.

different filling charge ratios $(40 \%, 60 \%, 80 \%$ and $100 \%)$ and different volume concentrations of graphene oxide/water nanofluids $(0.05 \%, 0.10 \%, 0.15 \%$ and $0.20 \%)$ in vertical orientation. The main outcomes were resumed below:

1) The heat transfer performance of a multi-heat pipe was apparently improved after the addition of GO nanoparticles in the working fluid.

2) $0.20 \%$ was the optimal volume concentration of $\mathrm{GO} /$ water nanofluids to achieve the maximal heat transfer enhancement for the filling ratios $40 \%, 60 \%, 80 \%$ and $100 \%$.

3) Compared with the pure water, the maximal decrease of evaporator temperature was $17.82 \%, 18.76 \%, 25.24 \%$ and $22.10 \%$ for $100 \%, 80 \%, 60 \%$ and $40 \%$ filling ratio at 
$0.20 \%$ volume concentration.

4) With increasing the input heat power and volumetric concentration of nanofluid, the overall thermal resistance of the heat pipe was increased.

5) The optimal thermal resistance of a multi-heat pipe was obtained at $100 \%$ filling charge ratio for $0.20 \%$ volume concentration.

6) For all working fluids and filling ratios, the overall heat transfer coefficient of this multi-heat pipe increased by increasing the input heat power.

7) For all filling ratios, the overall heat transfer coefficient improved with increasing the volumetric concentration of GO/water nanofluids.

8) The overall heat transfer coefficient depended greatly on the filling ratio, and the lower filling ratio (40\%) led to smaller heat transfer coefficient.

\section{Acknowledgements}

The first author would like to acknowledge the Cultural Affairs and Missions Sector, Ministry of Higher education, Egypt, for providing the financial support (PhD scholarship) for this research and the extended help of Thermal engineering laboratory under the Department of Mechanical System Engineering, Kumamoto University, Japan, for providing the facility for experimentation

\section{References}

[1] Kim, K. and Bang, I. (2016) Comparison of Flooding Limit and Thermal Performance of Annular and Concentric Thermosyphons at Different Fill Ratios. Applied Thermal Engineering, 99, 179-188. https://doi.org/10.1016/j.applthermaleng.2015.12.137

[2] Sarafraz, M. and Hormozi, F. (2014) Experimental Study on the Thermal Performance and Efficiency of a Copper Made Thermosyphon Heat Pipe Charged with Alumina-Glycol Based Nanofluids. Powder Technology, 266, 378-387.

https://doi.org/10.1016/j.powtec.2014.06.053

[3] Lips, S., Lefèvre, F. and Bonjour, J. (2010) Combined Effects of the Filling Ratio and the Vapour Space Thickness on the Performance of a Flat Plate Heat Pipe. International Journal of Heat and Mass Transfer, 53, 694-702.

https://doi.org/10.1016/j.ijheatmasstransfer.2009.10.022

[4] Mameli, M., Manno, V., Filippeschi, S. and Marengo, M. (2014) Thermal Instability of a Closed Loop Pulsating Heat Pipe: Combined Effect of Orientation and Filling Ratio. Experimental Thermal and Fluid Science, 59, 222-229.

https://doi.org/10.1016/j.expthermflusci.2014.04.009

[5] Barua, H., Ali, M., Nuruzzaman, M., Islam, M. and Feroz, C. (2013) Effect of Filling Ratio on Heat Transfer Characteristics and Performance of a Closed Loop Pulsating Heat Pipe. 5th BSME International Conference on Thermal Engineering, 56, 88-95. https://doi.org/10.1016/j.proeng.2013.03.093

[6] Pote, A. and Pachghere, P.R. (2015) Experimental Analysis on Thermal Performance of Closed Loop Pulsating Heat Pipe Using ZnO/Water Nanofluid. International Journal of Science and Research, 4, 235-239. https://www.ijsr.net/archive/v4i5/v4i5.php

[7] Verma, B., Yadav, V. and Srivastava, K. (2013) Experimental Studies on Thermal Performance of a Pulsating Heat Pipe with Methanol/DI Water. Journal of Electronics Cooling and Thermal Control, 3, 27-34. https://doi.org/10.4236/jectc.2013.31004 
[8] Qu, J., Wu, H. and Cheng, P. (2010) Thermal Performance of an Oscillating Heat Pipe with $\mathrm{Al}_{2} \mathrm{O}_{3}$-Water Nanofluids. International Communications in Heat and Mass Transfer, 37, 111-115. https://doi.org/10.1016/j.icheatmasstransfer.2009.10.001

[9] Lin, Y., Kang, S. and Chen, H. (2008) Effect of Silver Nano-Fluid on Pulsating Heat Pipe Thermal Performance. Applied Thermal Engineering, 28, 1312-1317. https://doi.org/10.1016/j.applthermaleng.2007.10.019

[10] Khandekar, S., Dollinger, N. and Groll, M. (2003) Understanding Operational Regimes of Closed Loop Pulsating Heat Pipes: An Experimental Study. Applied Thermal Engineering, 23, 707-719. https://doi.org/10.1016/S1359-4311(02)00237-5

[11] Salem, M., Bassily, M., Meakhail, T. and Torii, S. (2016) Experimental Investigation on Heat Transfer and Pressure Drop Characteristics of Graphene Oxide/Water Nanofluid in a Circular Tube. International Journal of Mechanical Engineering, 4, 12-22. http://ipasj.org/issue1.php?vol=Volume4Issue3\&Jname=4

[12] Hummers, W. Jr. and Offeman, R. (1958) Preparation of Graphitic Oxide. Journal of the American Chemical Society, 80, 1339. https://doi.org/10.1021/ja01539a017

Submit or recommend next manuscript to SCIRP and we will provide best service for you:

Accepting pre-submission inquiries through Email, Facebook, LinkedIn, Twitter, etc.

A wide selection of journals (inclusive of 9 subjects, more than 200 journals)

Providing 24-hour high-quality service

User-friendly online submission system

Fair and swift peer-review system

Efficient typesetting and proofreading procedure

Display of the result of downloads and visits, as well as the number of cited articles

Maximum dissemination of your research work

Submit your manuscript at: http://papersubmission.scirp.org/

Or contact wjnse@scirp.org 